\title{
Evaluating the efficacy of treatment options for anal intraepithelial neoplasia: a systematic review
}

\author{
Danielle R. L. Brogden ${ }^{1} \cdot$ Una Walsh ${ }^{1} \cdot$ Gianluca Pellino $^{2,3} \cdot$ Christos Kontovounisios $^{1}$ (D) $\cdot$ Paris Tekkis $^{1} \cdot$ Sarah C. Mills $^{1}$
}

Accepted: 8 September 2020 / Published online: 26 September 2020

(C) The Author(s) 2020

\begin{abstract}
Purpose Anal intraepithelial neoplasia (AIN) is the accepted precursor of anal squamous cell carcinoma (ASCC). There has long been a hypothesis that treating AIN may prevent ASCC. Many different treatment modalities have been suggested and studied. We conducted this systematic review to evaluate their efficacy and the evidence as to whether we can prevent ASCC by treating AIN. Methods MEDLINE and EMBASE were electronically searched using relevant search terms. All studies investigating the use of a single treatment for AIN that reported at least one end outcome such as partial or complete response to treatment, recurrence after treatment and/or ASCC diagnosis after treatment were included.

Results Thirty studies were included in the systematic review investigating 10 treatment modalities: 5\% imiquimod, 5-fluorouracil, cidofovir, trichloroacetic acid, electrocautery, surgical excision, infrared coagulation, radiofrequency ablation, photodynamic therapy and HPV vaccination. All treatment modalities demonstrated some initial regression of AIN after treatment; however, recurrence rates were high especially in HIV-positive patients. Many of the studies suffered from significant bias which prevented direct comparison.

Conclusions Although the theory persists that by inducing the regression of AIN, we may be able to reduce the risk of ASCC, there was no clinical evidence within the literature advocating that treating AIN does prevent ASCC.
\end{abstract}

Keywords HIV · Cancer · Anal intraepithelial neoplasia · AIN · Anal squamous cell carcinoma

\section{Introduction}

Anal intraepithelial neoplasia (AIN) is the accepted precursor to anal squamous cell carcinoma (ASCC). AIN and ASCC are due to dysplastic changes linked to human papillomavirus (HPV) infection, namely HPV 16, 18 and 31 . There are several different classification systems for describing AIN, one, typically used in the UK, uses 3 stages of dysplasia, ranging from low-grade AIN1 to high-grade AIN3 before the development of ASCC. Another describes AIN as either "highgrade AIN" (HGAIN) or "low-grade AIN" (LGAIN).

Christos Kontovounisios

c.konotovounisios@imperial.ac.uk

1 Chelsea and Westminster Hospitals, NHS Foundation Trust and Imperial College, London, UK

2 Colorectal Surgery, Vall d'Hebron University Hospital, Barcelona, Spain

3 Department of Advanced Medical and Surgical Sciences, Università degli Studi della Campania Luigi Vanvitelli, Naples, Italy
However, in 2012, the Lower Anogenital Squamous Terminology standardisation guidelines recommended the use of low- or high-grade "squamous intraepithelial lesion" (LSIL and HSIL), and many clinical centres have now adopted this as current practice [1].

By preventing HPV infection, it is thought that ASCC could become a preventable cancer; this is the rationale for adolescent HPV vaccination.

Patients with HIV represent an important high-risk group, especially in patients also reporting receptive anal intercourse, where the prevalence is reported to be as high as $87 \%$ in men [2] and $68 \%$ in women [3]. For this reason, much of the current evidence is derived from this population. Up to a third of patients in high-risk groups have high-grade AIN or ASCC [2, 3]. However, the rate of progression to ASCC from AIN is uncertain; Fuchs et al. (2016) states that up to a third of patients with high-grade AIN develop ASCC within 3 years [4], whereas other studies suggest that it is a much rarer occurrence, 7.4 cases per 100 years of follow-up [5].

There exists a hypothesis that by treating AIN in high-risk groups, we may prevent the development of ASCC. However, there is no consensus on which modality of AIN treatment is 
optimum and whether treatment for AIN is efficacious in preventing ASCC. Most treatments also have significant side effects that limit their acceptability for long-term use.

Many varied approaches and modalities are used to treat AIN. These include topical treatments, electrocautery, excision and/or destruction of lesion, laser ablation, photodynamic therapy, argon plasma coagulation, radiofrequency ablation and infrared coagulation. Topical treatments such as $5 \%$ imiquimod, 5-flurorouracil (5-FU) and 1\% cidofovir are some of the most studied.

With the many different treatment modalities used for AIN, it is unsurprising that little consensus exists in guidance for best clinical practice. We present a systematic review of all available AIN treatments in the literature with the aim of informing best practice guidance resulting in a more uniform approach to AIN treatment.

\section{Method}

This is a systematic review performed following the Preferred Reporting Items for Systematic Reviews and Meta-Analyses (PRISMA) Statement [6]. The systematic review protocol has been submitted to the International Prospective Register of Systematic Reviews (PROSPERO ID CRD42019135487).

\section{Inclusion criteria}

All studies investigating the use of a single treatment for AIN in any patients with a prior histological diagnosis of low-grade or high-grade AIN were included. To be included the papers required at least one of the end outcomes (partial or complete response to treatment, recurrence after treatment or ASCC diagnosis after treatment) to be reported. Any relevant peerreviewed case studies were included alongside comparative studies as there is little evidence currently on the best modality of AIN therapy and there would be a risk of bias towards more studied modalities if smaller studies in novel techniques were excluded.

\section{Exclusion criteria}

We excluded non-human studies and studies that were not available in the English language. We also excluded studies that did not meet the inclusion criteria, did not report any required end outcomes or studies that solely included patients with anal warts or patients without an established histological diagnosis of AIN. Single case reports and non-peer-reviewed abstracts and letters were excluded.

\section{Data sources and search strategies}

A MEDLINE and EMBASE search from inception to 18 April 2020 was conducted using the search strategy ("Anal Intraepithelial Neoplasia" OR "AIN" OR "LSIL" OR "HSIL" OR "LGAIN" OR "HGAIN") AND ("treatment" OR "therapy" OR "management"). Reference lists of included studies were also reviewed as well as current clinical guidelines and registered clinical trial registers. The titles and abstracts obtained from the electronic search were systematically reviewed against the inclusion criteria for relevant full papers to be obtained and read. On reading full papers, if they met the required inclusion criteria, they were included in the review. Duplicate papers were excluded on abstract review. DRLB performed the original data search as well as data extraction. UW performed a second independent data extraction for accuracy and also performed an independent check of abstract and full-paper review against inclusion criteria to ensure investigator agreement. To allow a fair comparison between studies, data included in systematic review was by default expressed as "intention to treat".

\section{Outcome definitions}

"Complete response" is defined as high- or low-grade AIN that on follow-up after treatment no AIN of any grade persists.

"Partial response" is defined as patients with high-grade AIN that after treatment have residual low-grade AIN only on follow-up.

"Recurrence" is defined as any grade of AIN that recurs at any grade after a previous complete response to AIN treatment or recurs at high-grade if there was a partial response to treatment on follow-up. When it was possible to separate patients with synchronous untreated lesions on follow-up from the reported recurrence rate, we did so to allow a fair comparison. This is clearly indicated on Table 1.

"Incidence of ASCC" is defined as any new diagnosis of ASCC on follow-up after previously treated AIN. Patients with a previous history on ASCC before treatment for AIN are excluded.

\section{Levels of evidence, quality and bias assessment}

Studies will be assessed and classified by the Oxford Centre for Evidence-Based Medicine Levels of Evidence 2011 [7].

A bias assessment will also be undertaken in all included studies. Randomised controlled trials will be assessed using the Cochrane Risk of Bias Version 2 Tool [8] and nonrandomised studies using the ROBINS-I tool [9]. 


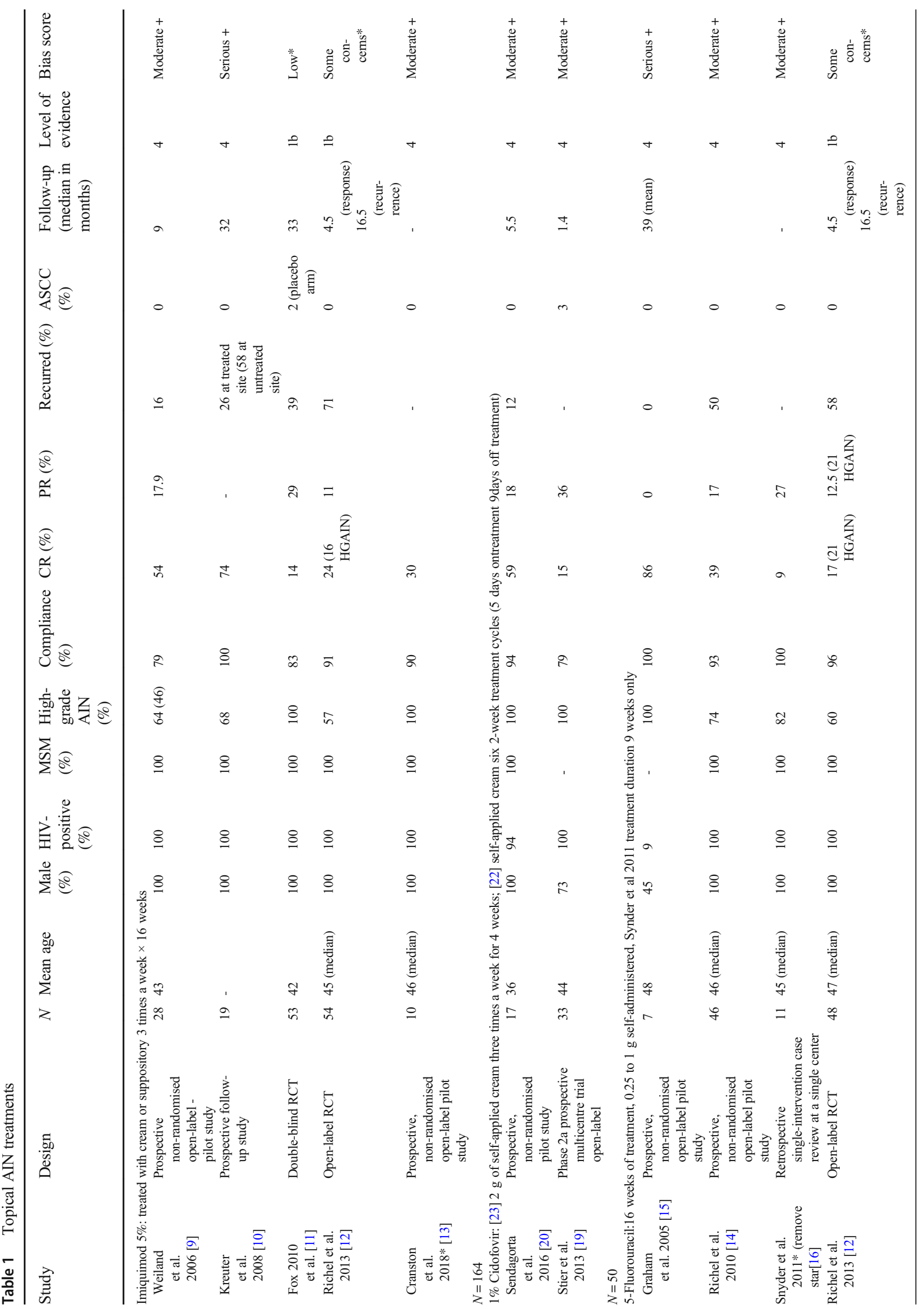




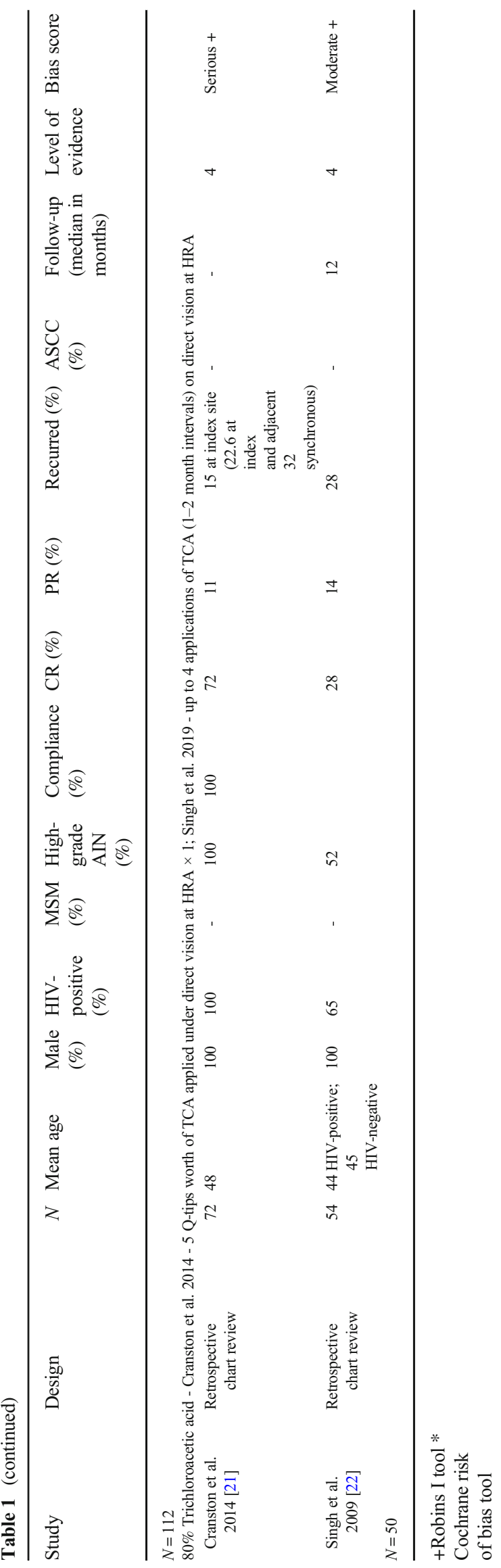

\section{Results}

\section{Description of studies}

A total of 4149 studies were identified after an electronic search of MEDLINE and EMBASE, 100 studies underwent abstract review and 82 studies underwent full-text review. Rationale for exclusion of studies is included in Fig. 1. Thirty-two studies were eventually included in the systematic review which included outcomes from imiquimod, 5-fluorouracil, cidofovir, trichloroacetic acid, electrocautery, surgical excision, infrared coagulation, radiofrequency ablation, photodynamic therapy and HPV vaccination. Unfortunately, argon plasma coagulation and laser ablation could not be included in the analysis as either only non-peer-reviewed abstracts were identified or the outcomes of single treatment modalities within the study were not reported.

A total of 26 included papers were classified as level 4 in the Oxford Centre for Evidence-Based Medicine Levels of Evidence 2011 and only 4 randomised controlled trials were identified.

A significant number of papers that were identified were published prior to the LAST criteria guidance therefore did not express their results as either HSIL or LSIL. To make a fair comparison, we will define "high-grade AIN" as either HGAIN, HSIL, AIN2 or AIN3 and "low-grade AIN" as LGAIN, LSIL or AIN1.

\section{Imiquimod}

5\% Imiquimod is a Toll-like Receptor 7 (TRL7) agonist that binds to TRL7 and activates the production of cytokines involved in the Th1 pathway, an immune response for virusinfected cells [10]. It is currently not licenced for use in treating AIN and is used off label. Its side effects include pain and bleeding on the area undergoing treatment which affects treatment compliance. Kreuter et al. (2007) demonstrated that levels of p16, a protein associated with HPV viral DNA, reduce with the use of imiquimod [11], so there is evidence that imiquimod does act on HPV-infected dysplastic cells, and could be a viable treatment for AIN.

Five studies were found which met the inclusion criteria $(N=164)$ [12-16]. All reported the response rate of imiquimod in HIV-positive "men who have sex with men" (MSM). Study participants had between 14 and $86 \%$ total response to treatment and 5-35\% partial response to treatment.

Despite many studies reporting local self-limiting adverse events such as bleeding, pain and anal irritation, overall compliance with treatment was good ranging from 79 to $100 \%$. Non-compliance when reported was more likely due to the study protocol and requirements on participants rather than adverse events. 
Fig. 1 PRISMA Table - results of the search strategy and reasons for exclusion

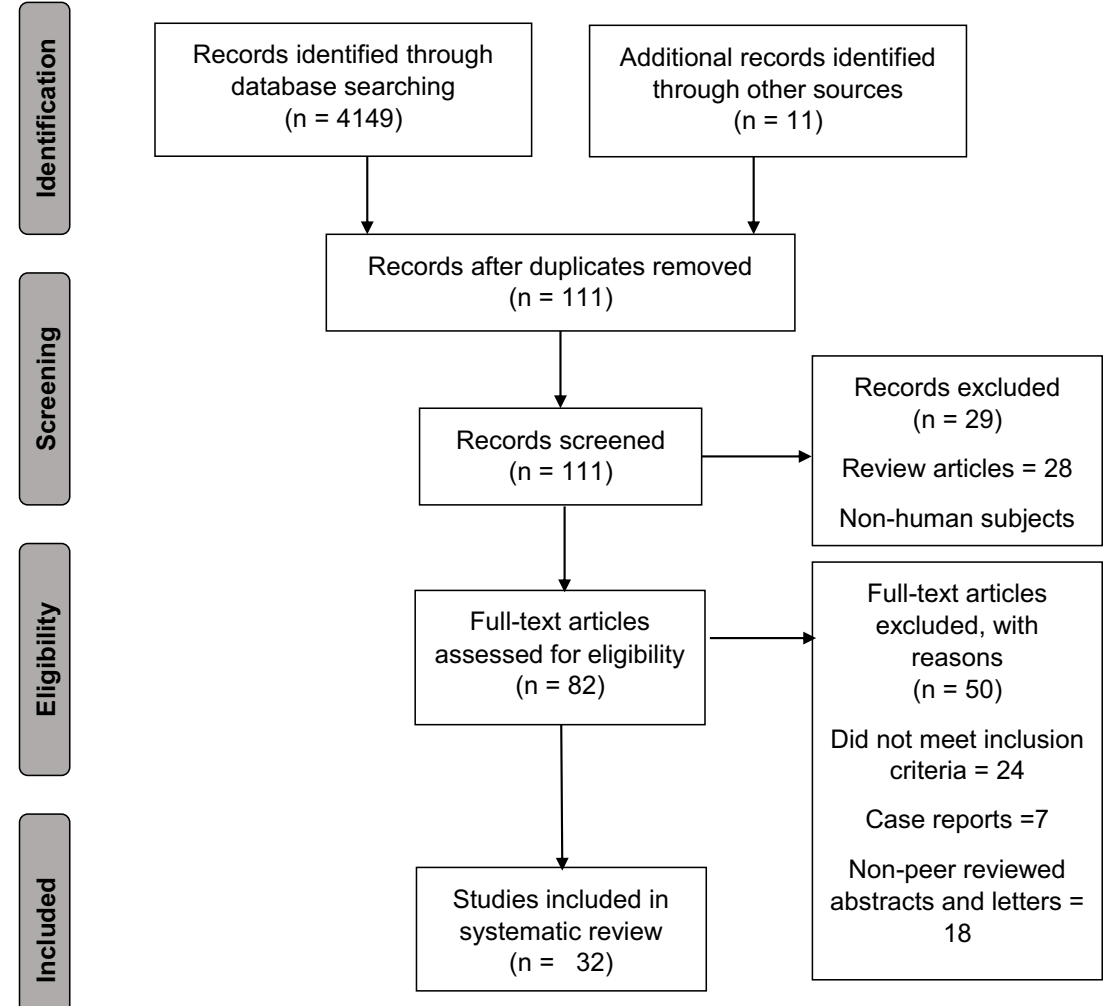

There was one randomised double-blind controlled trial comparing the use of imiquimod against placebo; this however only showed $14 \%$ complete response and $29 \%$ partial response with a $39 \%$ recurrence of high-grade AIN over median of 36 months in HIV-positive MSM [14]. This trial included a further 4 months of treatment for those in the treatment group who failed to respond and a crossover methodology to allow patients in the placebo arm access to imiquimod treatment.

There was also another randomised controlled trial that compared the use of imiquimod, 5-flurouracil and electrocautery in HIV-positive MSM. In this trial, Richel et al. (2013) showed that when treated with imiquimod, $24 \%$ of study participants had a complete response and $11 \%$ had a partial response. However, the participants also had a very high recurrence rate ( $71 \%$ of patients that achieved 72 weeks follow-up) [15].

It is also worth noting that a study which conducted a subset analysis of compliant patients only found a much higher complete response rate of $74 \%$ and a further $5 \%$ with a partial response [13].

The results suggest, although there appears to be an initial response to the imiquimod treatment, recurrence is high. The quality of evidence was also low with most studies reporting high level of bias. There is no evidence that imiquimod alone prevents the progression of AIN to ASCC, and due to the high levels of recurrence of high-grade AIN after treatment, it is unlikely that there is any benefit treating HIV-positive MSM.
Particularly as there is a paucity for evidence for repeated treatment and compliance could be problematic. There were no included studies investigating the use of imiquimod in HIV-negative patients or HIV-positive women.

\section{5-Fluorouracil}

5-FU is a pyrimidine analogue that inhibits thymidylate synthase which is involved in DNA synthesis [17]. It is licenced for use topically in basal cell carcinomas and actinic keratosis but is used off licence for the treatment of HPV-related intraepithelial neoplasia [17]. Similarly to imiquimod, side effects such as pain, discomfort and bleeding do affect treatment compliance.

Four studies examined the use of 5-fluorouracil in the treatment of AIN [18, 17, 15, 19]. Three studies included HIVpositive MSM as their only participants [17, 20, 19].

Study participants had between 9 and $86 \%$ complete response and 0-27\% partial response. Recurrence rates ranged from 9 to $58 \%$, and there were no new cases of ASCC reported in follow-up periods. The recurrence rate in HIV-positive MSM was between 0 and $58 \%$.

Richel et al. (2010) showed that the participants that did respond to treatment did have a significant reduction in HPV 16 DNA load, but $85 \%$ of participants experienced side effects from the treatment such as anal pain and proctitis, and the frequency of which $48 \%$ was significant [17]. 
There was one randomised controlled trial comparing 5fluorouracil with imiquimod and electrocautery in HIVpositive MSM [15]. Richel et al. (2013) showed that after treatment with 5-flurouracil, high-grade AIN completely responded in $21 \%$ and partially responded in $21 \%$, but $58 \%$ recurred over the follow-up period of 72 weeks [15].

Like imiquimod, it appears that 5 -fluorouracil does lead to some regression of AIN but with a greater variance in successful treatment. There was a significant rate of recurrence in HIV-positive MSM; however, when comparing like for like such as in Richel et al. (2013), the recurrence rate was less than that of imiquimod. More studies are required to assess its use in women and HIV-negative patients.

\section{Cidofovir}

One percent cidofovir is a cytidine nucleotide analogue which has shown to treat HPV in vitro [21]. It has been used successfully to treat anal warts, and pilot studies exist evaluating its use in AIN [22].

Two studies met the inclusion criteria, both studied the use of cidofovir on HIV-positive men and women. Sendagorta et al. (2016) reported 59\% had complete response with $18 \%$ recurrence rate [23]. In Stier et al. (2013), 15\% of patients with high-grade AIN had a complete response and $36 \%$ had a partial response; however, the follow-up was very short (6 weeks) and $97 \%$ of patients reported an adverse side effect and $21 \%$ of participants did not complete the treatment course due to severe side effects. In addition, progressive disease to ASCC was seen in $3 \%$.

Although treatment with cidofovir did lead to regression of AIN, there is currently insufficient evidence that cidofovir could be of benefit in preventing ASCC, as reported side effects may make long-term use unsustainable. The recurrence rates, when stated, in HIV-positive individuals were lower than other topical treatments.

\section{Trichloroacetic acid}

Trichloroacetic acid is a topical treatment that had been used successfully in the treatment of anal warts [24]. It is corrosive and is used to remove the top layer of treated skin. Like the other topical treatments, it is associated with side effects such as pain, bleeding and discomfort at the treated site.

Two studies met the inclusion criteria; Cranston et al. (2014) used $80 \%$ trichloroacetic acid in HIV-positive men with high-grade AIN, 72\% had either a complete response and $11 \%$ had a partial response with a $15 \%$ recurrence rate in 3-6 months of follow-up [25].

Singh et al. (2009) used 85\% trichloroacetic acid in HIVpositive men and women with AIN. Twenty-eight percent had a complete response and $15 \%$ had a partial response. Twenty- eight percent of patients treated had a recurrence of AIN ( $72 \%$ of patients who were compete responders) [24].

Although trichloroacetic acid does appear to regress AIN, there is insufficient evidence about its side effect profile or its long-term efficacy in the treatment of AIN.

\section{Surgical excision}

Surgical excision historically used to be a much more widely used practice due to the lack of other treatments available, and the hypothesis that full thickness excision prevented recurrence. This has now largely fallen out of fashion due to the increased risk of anal stenosis and poor sexual function. Therefore, only two historical papers could be included in this review; Scholefield et al. (1994) demonstrated a 30\% recurrence of high-grade AIN after wide local excision, whereas Brown et al. (1999) demonstrated an $18 \%$ had a recurrence rate. It is also important to note that this study reported that only $14 \%$ of patients achieved a complete excision without AIN identified on the margins [26].

\section{Electrocautery}

Electrocautery and surgical destruction are when suspicious lesions are cauterised using diathermy by the surgical or sexual health teams. There are risks of complications and side effects including pain, bleeding, synchronous lesions, anal stenosis and infection [27, 28].

Six studies met inclusion criteria [29, 28, 15, 30-32], 2 of which included HIV-positive MSM only [31, 30, 15, 28].

Complete response to electrocautery was between 22 and $78 \%$ and 2 studies reported that partial response occurred in between 7 and $26 \%$ of HIV-positive patients with high-grade AIN $[31,15]$.

Interestingly, two studies reported outcomes from HIVnegative patients; Marks et al. (2012) reported that $85 \%$ of HIV-negative patients had a complete response to electrocautery and were statistically less likely recur when compared with HIV-positive patients [32]. In Chang et al.'s study (2002), there were no HIV-negative patients that recurred after treatment [29].

Burgos et al. (2016) also identified that $39 \%$ of patients treated had a recurrence at the previously untreated site and that high recurrence rates could also be related to metachronous disease [31].

Electrocautery is less well-tolerated in terms of sexual function and quality of life at 20 weeks after treatment when compared with imiquimod and 5-FU [33].

Like topical treatments, electrocautery appears to have some effect in treating AIN, however, with a high recurrence rate particularly in HIV-positive patients. Electrocautery may be more successful in HIV-negative individuals. 
The majority of cauterisations are performed under local anaesthetic in clinic [31] which raises the question whether this technique would be more successful if performed under sedation or under general anaesthetic allowing optimal views and access to lesions.

\section{Infrared coagulation}

Infrared coagulation (IRC) is a newer technique that although is associated with pain and bleeding, the symptoms are reported to be less severe than other ablative treatments (Table 2) [27]. It involves applying a probe that directs short bursts of infrared light to areas of concern [25].

Six studies were found in the literature all with varying response rates; $3-71 \%$ of patients had a complete response, whereas $6-69 \%$ of patients had a partial response [34-37]. Interestingly, Goldstone et al. (2011) reported recurrence rates which were considerably higher in HIV-positive MSM when compared with that of HIV-negative MSM; however, the majority of this burden of recurrence was caused by metachronous lesions rather than recurrence of lesions recently treated by infrared coagulation [36].

One randomised controlled trial was identified where HIVpositive patients with HSIL were randomised to either receive IRC or routine observation with high-resolution anoscopy [38]. The results in this trial were promising; $71 \%$ of patients in the treatment arm were dysplasia-free at 12 months compared with $28 \%$ in the active observation arm $(p<0.001)$. The trial itself appeared to be well-conducted and only limited by its inability to blind patients to the intervention received. There were no new cancers identified in either treatment arm, but the study was underpowered for this outcome.

Two patients in the placebo arm of one study developed ASCC on follow-up; overall they demonstrated that infrared coagulation did result in a reduction in high-grade disease with ASCC on follow-up; however, despite this, they did not separately analyse risk of ASCC between study arms. It is unlikely, due to small study numbers, that this would be statistically significant [34].

\section{Radiofrequency ablation}

More frequently used in endoscopy units to treat dysplasia is related to Barrett's oesophagus; Radiofrequency ablation uses multiple electrodes to provide radiofrequency energy to cause the coagulation of tissue at high temperatures.

Radiofrequency ablation (RFA) as yet has only been reported in the literature by one author. Goldstone et al. (2017) reported their outcomes of hemi-circumferential [39] as well as circumferential RFA for high-grade AIN [40].

In one study, Goldstone et al. (2017) performed hemicircumferential RFA in HIV-negative patients with highgrade AIN and reported 14\% recurrence after 1 year in
RFA-treated areas. In the other study, Goldstone et al. (2017) performed circumferential RFA in patients with highgrade AIN (90\% were HIV-positive). On the first treatment, $40 \%$ of patients had persistent lesions; however, after a further treatment, they achieved a $0 \%$ recurrence rate at 1 year followup in 10 patients.

Although this sounds promising as a treatment modality, more research needs to be completed to be able to comment with confidence on the use of RFA for high-grade AIN.

\section{Photodynamic therapy}

Photodynamic therapy involves the ablation of AIN by applying light sources to areas previously photosensitized [41]. Photosentisation can be undertaken systemically, by the IV administration of a photosensitising agent, or topically by the application of the agent on the area of concern [41]. Van der Snoek et al. (2012) advises that the advantage of using photodynamic therapy is that light can be applied more evenly with higher precision than other ablative methods [41].

Two studies were identified that met inclusion criteria; Van der Snook et al. (2012) used systemic photodynamic therapy to treat HIV-positive MSM with high-grade AIN. Twenty percent had a complete response to treatment and $27 \%$ had a partial response. There was a $20 \%$ recurrence rate and $6 \%$ of patients had a worsening of dysplasia during treatment [41].

Welbourn et al. (2014) also reported outcomes of topical, systemic, and a combined treatment on 13 patients and demonstrated a $40 \%$ complete response. However, there was little information on study participants; therefore, it is unclear whether the population included in the study is generalisable to other studies [42].

\section{HPV vaccination}

The quadrivalent HPV 6, 11, 16 and 18 vaccine (Gardasil, Merck) has been proposed as a method of secondary prevention for the recurrence of high-grade AIN. This is based on studies such as Palefsky et al. (2006) that demonstrated 33\% complete or partial response to an experimental quadrivalent vaccination in high-grade AIN [43].

More recently, Swedish et al. (2012) have shown that the quadrivalent vaccination prevents the recurrence of highgrade AIN after targeted destruction [44]. However, this is contrary to a randomised controlled trial of patients with high-grade AIN that received the quadrivalent vaccine or a placebo vaccine. Unfortunately, the trial was stopped early due to finding no benefit between its treatment arms after median follow-up of 3.4 years [45]. It is therefore unlikely that HPV vaccination is an effective treatment for highgrade AIN. 


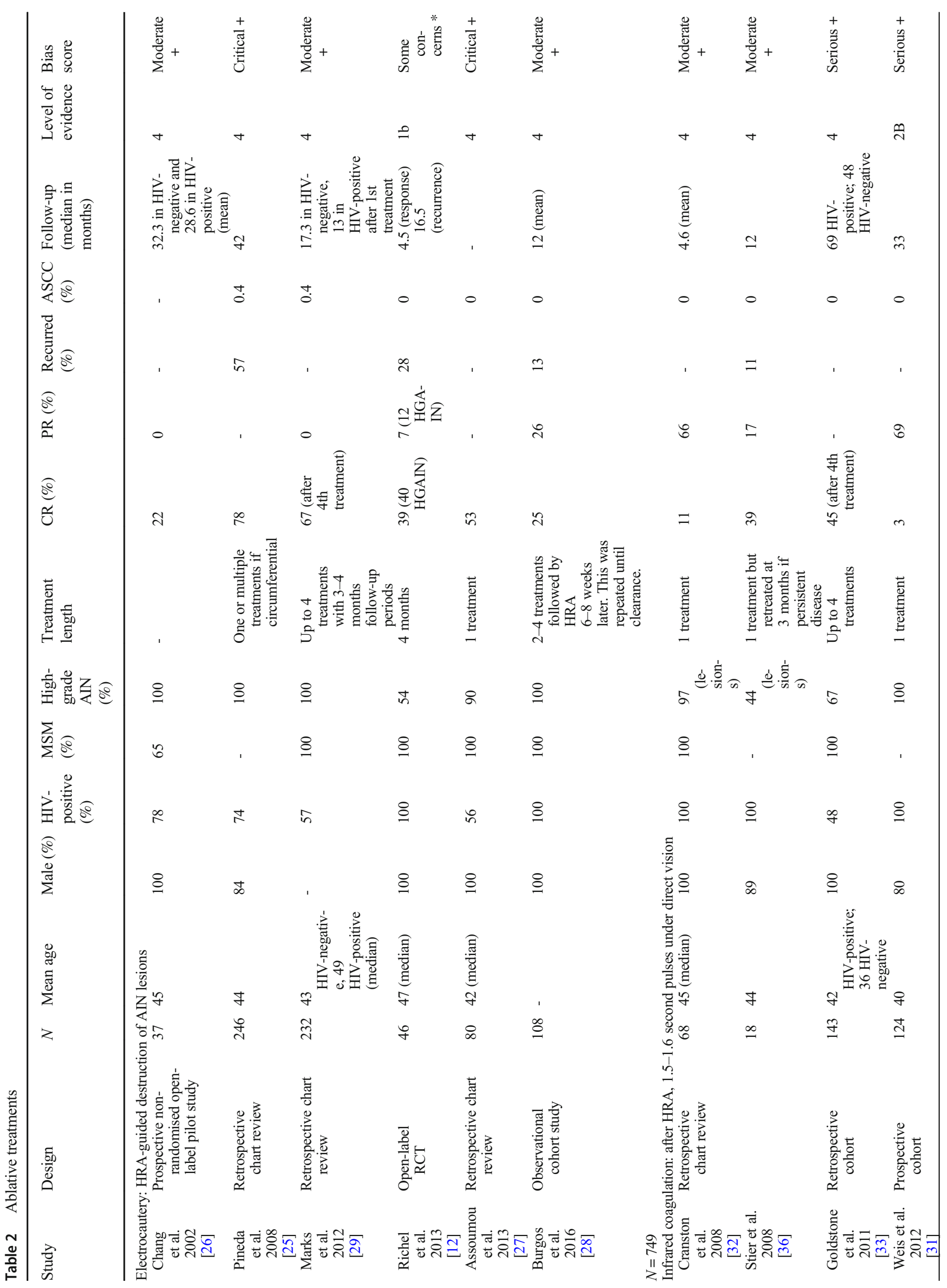




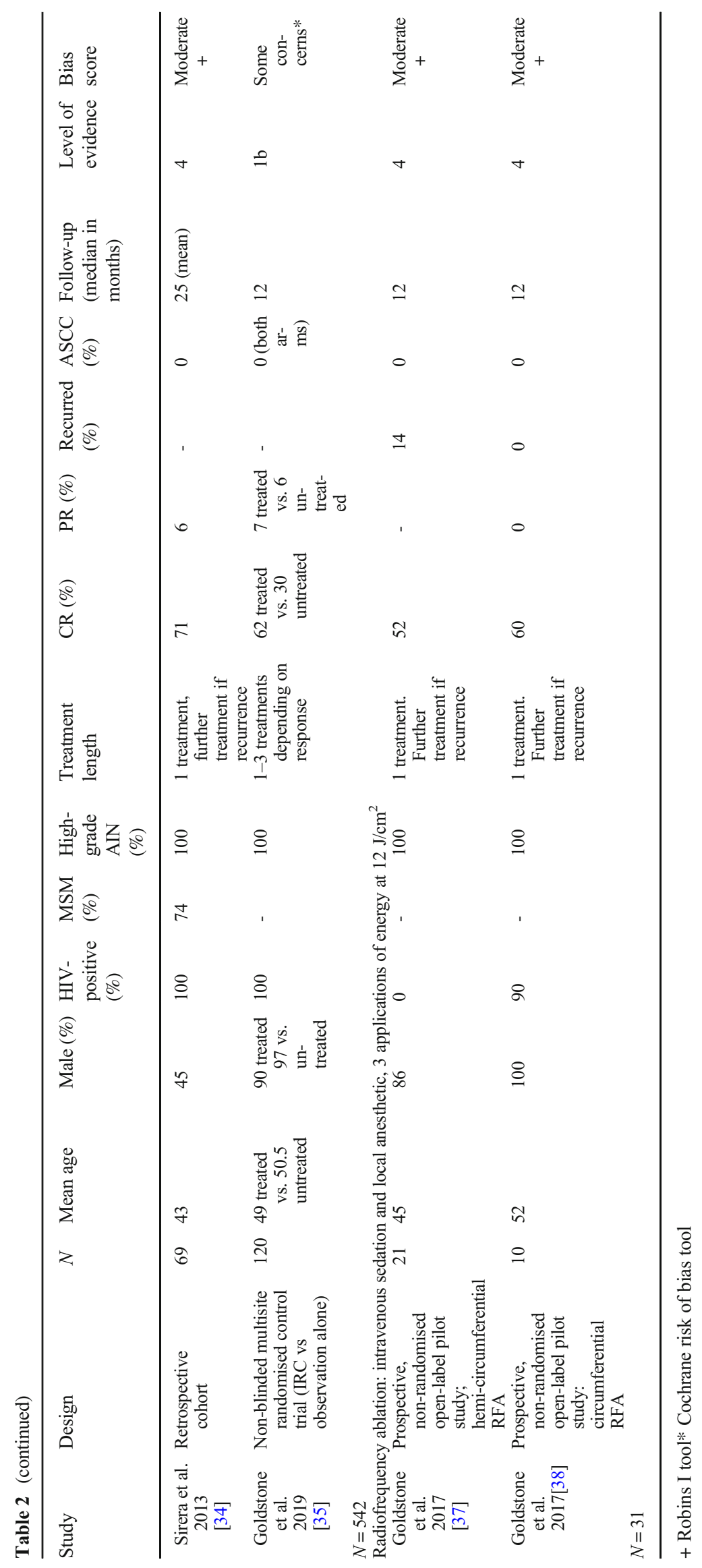




\section{Discussion}

This systematic review has identified several treatment modalities that do induce regression of AIN; however, the majority of the studies were underpowered to identify whether there is any evidence that treating AIN could prevent the development of ASCC in the long term. Furthermore, as the recurrence rates are high, and treatment are often associated with poor compliance due to severe side effects, it is possible that treating AIN could result in more harm than overall benefit (Tables 1,2 and 3).

The majority of studies identified to be included in his systematic review were also of poor quality and likely to lend to bias. For example, many studies were inconsistent in how they defined high-grade AIN and not all studies followed up all patients and reported their outcomes in an "intention to treat" manner. Some studies were also limited in power due to their sample sizes and length of follow-up time. For this reason, we have chosen not to undertake a meta-analysis of the results.

There was also some difficulty identifying comparable recurrence rates between studies. Not all studies reported whether their recurrences were at a treated site or whether they developed another focus of dysplasia at a synchronous or metachronous site. The high recurrence rates could easily be driven by a continuing HPV perineal infection. Better study methodology is required to be able to determine whether treatment of each individual lesions is efficacious. A whole-field approach like the pilot study completed by Goldstone et al. (2017) which treated the entire anal squamocolumnar junction with radiofrequency ablation, if well-tolerated long-term, may be the best option for the future treatment of high-grade AIN.

Only four randomised controlled trials were identified, and unfortunately, they all described different treatments: one examining the use of imiquimod compared with placebo [14], one comparing quadrivalent HPV vaccination with placebo [45], a further trails comparing infrared coagulation against active monitoring [38] and a three-armed trial by Richel et al. (2013) comparing imiquimod, 5-fluorouracil and electrocautery [15]. The different treatment modalities in each trial meant their results could not be compared directly with each other. All four trials were of good quality however; therefore, their findings are most likely to be accurate. On balance, the clinical trial recommendations on the topical treatments for AIN in HIV-positive MSM are similar; Fox et al. (2010) reported $43 \%$ response to imiquimod treatment compared with that of Richel et al. (2013) who had a $46 \%$ response. The recurrence rates were not similar however $39 \%$ compared with $71 \%$ respectively $[14,15]$.

Goldstone et al. (2019) demonstrated very promising results with infrared coagulation achieving statistically higher rates of complete response compared with active monitoring alone with $71 \%$ of treated patients being disease-free at
12 months [38]. Their treatment protocol was quite comprehensive, with $45 \%$ of treated patients receiving 2 or 3 treatments over the study period. It may be that to achieve a good outcome with ablative therapies that multiple treatments may be required in the long term. It would be interesting to see whether patients who were disease-free at the end of the study remained so in the long term or whether they will later require further ablative therapies in the future.

Richel et al.'s study (2013) was the only study identified that compared multiple treatments; they demonstrated a significantly higher complete response rate in electrocautery compared with 5-fluorouracil $(p=0.008)$. Electrocautery also resulted in a higher complete response rate compared with imiquimod, but this was not statistically significant (39\% vs. $24 \%, p=0.10$ ) [15]. There was no statistically significant difference in recurrence rate between treatment modalities [15].

We are aware that some clinical centres use topical treatments as an adjunct to ablative therapies; however, the evaluation of this treatment pathway is beyond the scope of this review which is limited to the study of single treatment modalities. It is possible that a combination of treatment modalities may have a better long-term result, and further studies should be undertaken with this in mind.

These findings correspond with recent guidelines published. The Association of Coloproctology of Great Britain and Ireland suggests that HIV-positive MSM would most likely benefit from electrocautery but did not state a specific preference on topical treatments [46], whereas The American Society of Colon and Rectal Surgeons also advises no preference between ablative treatments, imiquimod, 5 -fluorouracil, trichloroacetic acid and cidofovir for the treatment of low- and high-grade dysplasias [47]. The Italian Society of Colorectal Surgery recommends that topical treatments could be a good compromise between surgical treatment and the watch and wait approach. They feel strongly that a method of treatment should be undertaken for all high-grade disease but like the American and British guidelines expressed no other preference on the best treatment modality [48].

The majority of the available evidence is based on HIVpositive MSM, which lends to the possibility that different treatments may be more successful in HIV-negative populations. Indeed, several studies that did include a comparison between populations suggested that HIV-negative patients had a lower recurrence rate [36, 32, 29] More research is required in comparing different patient subpopulations with AIN.

There also exists a high possibility of publication bias as many single centres are reporting their outcomes in non-peerreviewed abstracts that could not be included in this analysis. Other centres are reporting novel techniques such as Goldstone et al.'s (2017) use of radiofrequency ablation. As there is no other corresponding research in other centres into this treatment modality, although they demonstrated good outcomes, generalisability is potentially limited. 


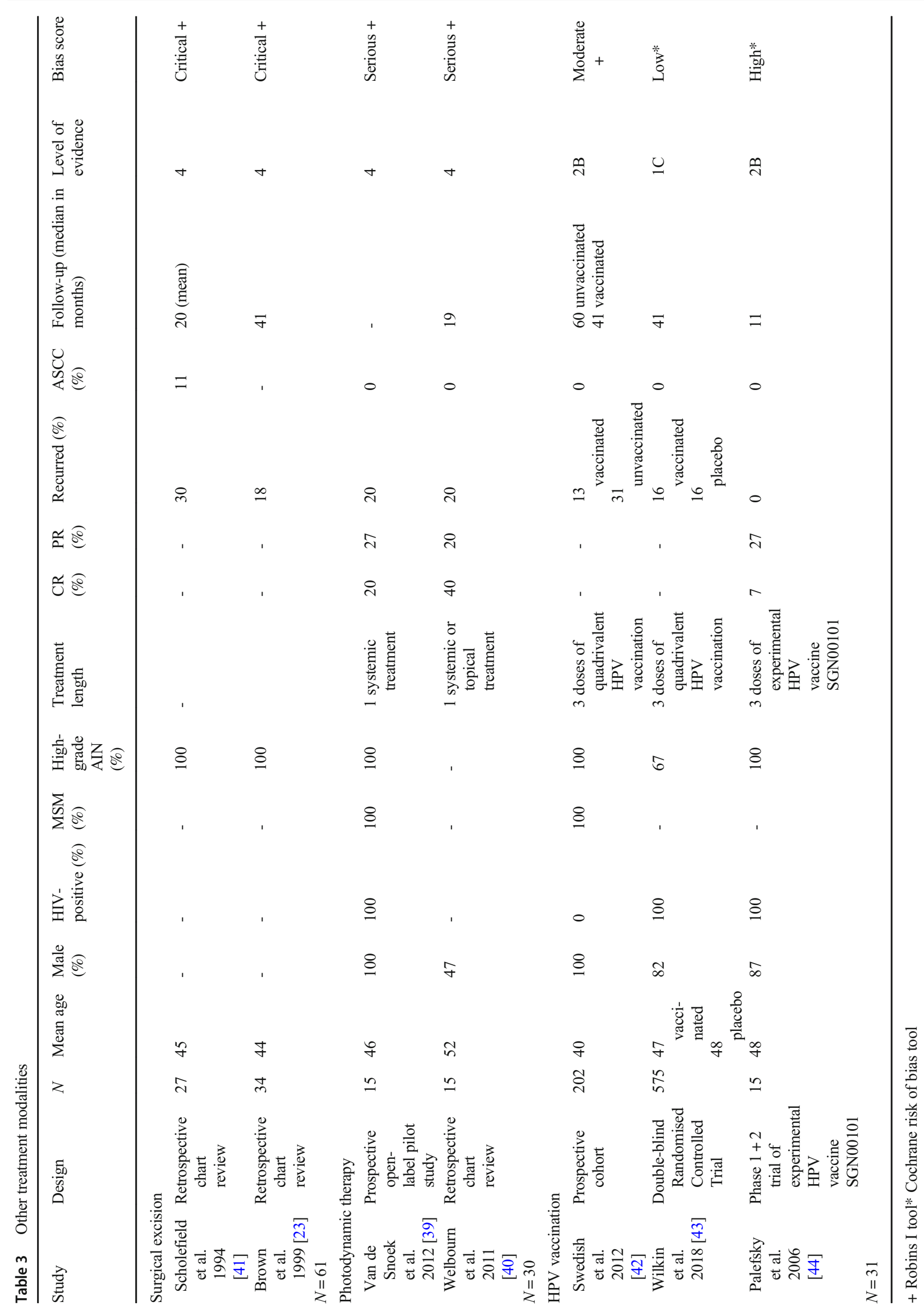


In 2014, the Anal Cancer HSIL Outcomes Research (ANCHOR) study, a multicentre stage III randomised controlled trial began recruiting HIV-positive patients in the USA (NCT02135419). The study is randomising patients with a new diagnosis of high-grade AIN to receive either ablative treatment, topical treatment or watchful waiting with time to ASCC incidence as the trial's primary outcome measure. It is hoped that this trial will be able to clarify whether there are long-term benefits to treating HIV-positive patients with highgrade AIN.

\section{Conclusion}

There is no single treatment modality that has a good enough evidence base to recommend its use as the gold standard in the treatment of AIN. Nearly all of the studies included in this review were able to demonstrate AIN regression, but recurrence rates were often high and the evaluation of the long-term efficacy of the treatments was limited by short follow-up times. Although the theory persists that by inducing the regression of AIN, we may be able to reduce the risk of ASCC, there was no clinical evidence within the literature advocating that treating AIN does prevent ASCC. Further clinical trials are required at a larger scale with longer follow-up times that include HIV-negative as well as HIV-positive patients.

Code availability Not applicable.

Availability of data and material Not applicable.

\section{Compliance with ethical standards}

Conflicts of Interest The authors declare that they have no conflicts of interest.

Ethical approval No ethical approval was required for this research.

Consent to participate Not applicable.

Consent for publication All named authors have contributed to this research and gave their consent for publication.

Open Access This article is licensed under a Creative Commons Attribution 4.0 International License, which permits use, sharing, adaptation, distribution and reproduction in any medium or format, as long as you give appropriate credit to the original author(s) and the source, provide a link to the Creative Commons licence, and indicate if changes were made. The images or other third party material in this article are included in the article's Creative Commons licence, unless indicated otherwise in a credit line to the material. If material is not included in the article's Creative Commons licence and your intended use is not permitted by statutory regulation or exceeds the permitted use, you will need to obtain permission directly from the copyright holder. To view a copy of this licence, visit http://creativecommons.org/licenses/by/4.0/.

\section{References}

1. Darragh TM, Colgan TJ, Thomas Cox J, Heller DS, Henry MR, Luff RD, McCalmont T, Nayar R, Palefsky JM, Stoler MH, Wilkinson EJ, Zaino RJ, Wilbur DC (2013) The Lower Anogenital Squamous Terminology Standardization project for HPV-associated lesions: background and consensus recommendations from the College of American Pathologists and the American Society for Colposcopy and Cervical Pathology. Int J Gynecol Pathol 32(1):76-115. https://doi.org/10.1097/PGP. 0b013e31826916c7

2. Gaisa M, Sigel K, Hand J, Goldstone S (2014) High rates of anal dysplasia in HIV-infected men who have sex with men, women, and heterosexual men. AIDS 28(2):215-222. https://doi.org/10. 1097/QAD.0000000000000062

3. Bernard JE, Butler MO, Sandweiss L, Weidner N (2008) Anal intraepithelial neoplasia: correlation of grade with p16INK4a immunohistochemistry and HPV in situ hybridization. Appl Immunohistochem Mol Morphol 16(3):215-220. https://doi.org/ 10.1097/PAI.0b013e3181454a95

4. Fuchs W, Wieland U, Skaletz-Rorowski A, Brockmeyer NH, Swoboda J, Kreuter A, Michalik C, Potthoff A, Competence Network for HA (2016) The male ScreenING Study: prevalence of HPV-related genital and anal lesions in an urban cohort of HIVpositive men in Germany. J Eur Acad Dermatol Venereol 30(6): 995-1001. https://doi.org/10.1111/jdv.13539

5. Tong WWY, Jin F, McHugh LC, Maher T, Sinclair B, Grulich AE, Hillman RJ, Carr A (2013) Progression to and spontaneous regression of high-grade anal squamous intraepithelial lesions in HIVinfected and uninfected men. AIDS 27(14):2233-2243. https:// doi.org/10.1097/QAD.0b013e3283633111

6. Moher D, Liberati A, Tetzlaff J, Altman DG, The PG (2009) Preferred reporting items for systematic reviews and meta-analyses: the PRISMA statement. PLoS Med 6(7):e1000097. https://doi.org/ 10.1371/journal.pmed.1000097

7. Medicine OCfE-B (2011) The Oxford 2011 levels of evidence. https://www.cebm.net/2016/05/ocebm-levels-of-evidence/. Accessed 28/05/2019 2019

8. Sterne JACSJ, Page MJ, Elbers RG, Blencowe NS, Boutron I, Cates CJ, Cheng H-Y, Corbett MS, Eldridge SM, Hernán MA, Hopewell S, Hróbjartsson A, Junqueira DR, Jüni P, Kirkham JJ, Lasserson T, Li T, McAleenan A, Reeves BC, Shepperd S, Shrier I, Stewart LA, Tilling K, White IR, Whiting PF, Higgins JPT (2019) RoB 2: a revised tool for assessing risk of bias in randomised trials. BMJ 366:14898

9. Sterne JACHM, Reeves BC, Savović J, Berkman ND, Viswanathan M, Henry D, Altman DG, Ansari MT, Boutron I, Carpenter JR, Chan AW, Churchill R, Deeks JJ, Hróbjartsson A, Kirkham J, Jüni P, Loke YK, Pigott TD, Ramsay CR, Regidor D, Rothstein HR, Sandhu L, Santaguida PL, Schünemann HJ, Shea B, Shrier I, Tugwell P, Turner L, Valentine JC, Waddington H, Waters E, Wells GA, Whiting PF, Higgins JPT (2016) ROBINSI: a tool for assessing risk of bias in non-randomized studies of interventions. BMJ 355(4919)

10. Mahto M, Nathan M, O'Mahony C (2010) More than a decade on: review of the use of imiquimod in lower anogenital intraepithelial neoplasia. Int J STD AIDS 21(1):8-16. https://doi.org/10.1258/ijsa. 2009.009309

11. Kreuter A, Wieland U, Gambichler T, Altmeyer P, Pfister H, Tenner-Racz K, Racz P, Potthoff A, Brockmeyer NH, German Network of Competence HA (2007) p16ink4a expression decreases during imiquimod treatment of anal intraepithelial neoplasia in human immunodeficiency virus-infected men and correlates with the decline of lesional high-risk human papillomavirus DNA load. Br J Dermatol 157 (3):523-530 
12. Wieland U, Brockmeyer NH, Weissenborn SJ, Hochdorfer B, Stucker M, Swoboda J, Altmeyer P, Pfister H, Kreuter A (2006) Imiquimod treatment of anal intraepithelial neoplasia in HIVpositive men. Arch Dermatol 142(11):1438-1444

13. Kreuter A, Potthoff A, Brockmeyer NH, Gambichler T, Stucker M, Altmeyer P, Swoboda J, Pfister H, Wieland U, German Competence Network HA (2008) Imiquimod leads to a decrease of human papillomavirus DNA and to a sustained clearance of anal intraepithelial neoplasia in HIV-infected men. J Investig Dermatol 128(8):2078-2083. https://doi.org/10.1038/jid.2008.24

14. Fox PA, Nathan M, Francis N, Singh N, Weir J, Dixon G, Barton SE, Bower M (2010) A double-blind, randomized controlled trial of the use of imiquimod cream for the treatment of anal canal highgrade anal intraepithelial neoplasia in HIV-positive MSM on HAART, with long-term follow-up data including the use of open-label imiquimod. AIDS 24(15):2331-2335. https://doi.org/ 10.1097/QAD.0b013e32833d466c

15. Richel O, de Vries HJ, van Noesel CJ, Dijkgraaf MG, Prins JM (2013) Comparison of imiquimod, topical fluorouracil, and electrocautery for the treatment of anal intraepithelial neoplasia in HIVpositive men who have sex with men: an open-label, randomised controlled trial. Lancet Oncol 14(4):346-353. https://doi.org/10. 1016/s1470-2045(13)70067-6

16. Cranston RD, Baker JR, Siegel A, Brand RM, Janocko L, McGowan I (2018) A pilot study of the immunologic, virologic, and pathologic consequences of intra-anal 5\% imiquimod in HIV1-infected men with high-grade squamous intraepithelial lesions. Dis Colon Rectum 61(3):298-305. https://doi.org/10.1097/dcr. 0000000000000991

17. Richel O, Wieland U, de Vries HJ, Brockmeyer NH, van Noesel C, Potthoff A, Prins JM, Kreuter A (2010) Topical 5-fluorouracil treatment of anal intraepithelial neoplasia in human immunodeficiency virus-positive men. Br J Dermatol 163(6):1301-1307. https://doi. org/10.1111/j.1365-2133.2010.09982.x

18. Graham BD, Jetmore AB, Foote JE, Arnold LK (2005) Topical 5fluorouracil in the management of extensive anal Bowen's disease: a preferred approach. Dis Colon Rectum 48(3):444 450. https:// doi.org/10.1007/s10350-004-0901-8

19. Snyder SM, Siekas L, Aboulafia DM (2011) Initial experience with topical fluorouracil for treatment of HIV-associated anal intraepithelial neoplasia. J Int Assoc Phys AIDS Care (Chicago, I11 : 2002) 10(2):83-88. https://doi.org/10.1177/ 1545109710382578

20. Richel O, Hallensleben ND, Kreuter A, van Noesel CJ, Prins JM, de Vries HJ (2013) High-resolution anoscopy: clinical features of anal intraepithelial neoplasia in HIV-positive men. Dis Colon Rectum 56(11):1237-1242. https://doi.org/10.1097/DCR. 0b013e3182a53568

21. Safrin S, Cherrington J, Jaffe HS (1997) Clinical uses of cidofovir. 7 (3):145-156https://doi.org/10.1002/(sici)1099-1654(199709)7: 3<145::Aid-rmv196>3.0.Co;2-0

22. Stier EA, Goldstone SE, Einstein MH, Jay N, Berry JM, Wilkin T, Lee JY, Darragh TM, Da Costa M, Panther L, Aboulafia D, Palefsky JM (2013) Safety and efficacy of topical Cidofovir to treat high-grade perianal and vulvar intraepithelial neoplasia in HIVpositive men and women. AIDS (London, England) 27(4):545551. https://doi.org/10.1097/QAD.0b013e32835a9b16

23. Sendagorta E, Bernardino JI, Alvarez-Gallego M, Feito M, Feltes R, Beato MJ, Perez-Molina JA, Yllescas M, Diaz-Almiron M, Arribas JR, Gonzalez-Garcia J, Herranz P, Group CGS (2016) Topical cidofovir to treat high-grade anal intraepithelial neoplasia in HIV-infected patients: a pilot clinical trial. AIDS 30(1):75-82. https://doi.org/10.1097/QAD.0000000000000886

24. Singh JC, Kuohung V, Palefsky JM (2009) Efficacy of trichloroacetic acid in the treatment of anal intraepithelial neoplasia in HIVpositive and HIV-negative men who have sex with men. J Acquir
Immune Defic Syndr (1999) 52(4):474-479. https://doi.org/10. 1097/QAI.0b013e3181bc0f10

25. Cranston RD, Baker JR, Liu Y, Wang L, Elishaev E, Ho KS (2014) Topical application of trichloroacetic acid is efficacious for the treatment of internal anal high-grade squamous intraepithelial lesions in HIV-positive men. Sex Transm Dis 41(7):420-426. https:// doi.org/10.1097/olq.0000000000000145

26. Brown SR, Skinner P, Tidy J, Smith JH, Sharp F, Hosie KB (1999) Outcome after surgical resection for high-grade anal intraepithelial neoplasia (Bowen's disease). Br J Surg 86(8):1063-1066

27. Willems N, Libois A, Nkuize M, Feoli F, Delforge M, DeWit S (2017) Treatment of anal dysplasia in HIV-positive men who have sex with men in a large AIDS reference centre. Acta Clin Belg 72(1):29-35. https://doi.org/10.1080/17843286.2015.1116725

28. Pineda CE, Berry JM, Jay N, Palefsky JM, Welton ML (2008) High-resolution anoscopy targeted surgical destruction of anal high-grade squamous intraepithelial lesions: a ten-year experience. Dis Colon Rectum 51(6):829-837. https://doi.org/10.1007/s10350008-9233-4

29. Chang GJ, Berry JM, Jay N, Palefsky JM, Welton ML (2002) Surgical treatment of high-grade anal squamous intraepithelial lesions: a prospective study. Dis Colon Rectum 45(4):453-458. https://doi.org/10.1007/s10350-004-6219-8

30. Assoumou SA, Panther LA, Feng Y, Gelman RS, Fugelso DK, Mayer KH (2013) Treatment of high-grade anal dysplasia in highrisk patients: outcome at an urban community health centre. Int $\mathrm{J}$ STD AIDS 24(2):134-138. https://doi.org/10.1177/ 0956462412472298

31. Burgos J, Curran A, Landolfi S, Navarro J, Tallada N, Guelar A, Crespo M, Ocana I, Ribera E, Falco V (2016) The effectiveness of electrocautery ablation for the treatment of high-grade anal intraepithelial neoplasia in HIV-infected men who have sex with men. HIV Medicine 17(7):524-531. https://doi.org/10.1111/hiv. 12352

32. Marks DK, Goldstone SE (2012) Electrocautery ablation of highgrade anal squamous intraepithelial lesions in HIV-negative and HIV-positive men who have sex with men. J Acquir Immune Defic Syndr 59(3):259-265. https://doi.org/10.1097/QAI. 0b013e3182437469

33. Siegenbeek Van Heukelom ML, Richel O, Nieuwkerk PT, De Vries HJC, Prins JM (2016) Health-related quality of life and sexual functioning of HIV-positive men who have sex with men who are treated for anal intraepithelial neoplasia. Dis Colon Rectum 59(1): 42-47. https://doi.org/10.1097/DCR.0000000000000511

34. Weis SE, Vecino I, Pogoda JM, Susa JS (2012) Treatment of highgrade anal intraepithelial neoplasia with infrared coagulation in a primary care population of HIV-infected men and women. Dis Colon Rectum 55(12):1236-1243. https://doi.org/10.1097/DCR. 0b013e31826d5cb5

35. Cranston RD, Hirschowitz SL, Cortina G, Moe AA (2008) A retrospective clinical study of the treatment of high-grade anal dysplasia by infrared coagulation in a population of HIV-positive men who have sex with men. Int J STD AIDS 19(2):118-120. https:// doi.org/10.1258/ijsa.2007.005665

36. Goldstone RN, Goldstone AB, Russ J, Goldstone SE (2011) Longterm follow-up of infrared coagulator ablation of anal high-grade dysplasia in men who have sex with men. Dis Colon Rectum 54(10):1284-1292. https://doi.org/10.1097/DCR. 0b013e318227833e

37. Sirera G, Videla S, Pinol M, Coll J, Garcia-Cuyas F, Vela S, Canadas M, Darwich L, Perez N, Gel S, Cobarsi P, Clotet B, Group H-HS (2013) Long-term effectiveness of infrared coagulation for the treatment of anal intraepithelial neoplasia grades 2 and 3 in HIV-infected men and women. AIDS 27(6):951-959. https://doi. org/10.1097/QAD.0b013e32835e06c1 
38. Goldstone SE, Lensing SY, Stier EA, Darragh T, Lee JY, van Zante A, Jay N, Berry-Lawhorn JM, Cranston RD, Mitsuyasu R, Aboulafia D, Palefsky JM, Wilkin T (2019) A randomized clinical trial of infrared coagulation ablation versus active monitoring of intra-anal high-grade dysplasia in adults with human immunodeficiency virus infection: an AIDS Malignancy Consortium Trial. Clin Infect Dis 68(7):1204-1212. https://doi.org/10.1093/cid/ciy615

39. Goldstone RN, Hasan SR (1999) Goldstone SE (2017) Brief report: radiofrequency ablation therapy for anal intraepithelial neoplasia: results from a single-center prospective pilot study in HIV+ participants. J Acquir Immune Defic Syndr 76(4):e93-e97. https://doi. org/10.1097/QAI.0000000000001535

40. Goldstone RN, Hasan SR, Drury S, Darragh TM, van Zante A, Goldstone SE (2017) A trial of radiofrequency ablation for anal intraepithelial neoplasia. Int J Color Dis 32(3):357-365. https:// doi.org/10.1007/s00384-016-2679-2

41. van der Snoek EM, den Hollander JC, Aans JB, Sterenborg HJCM, van der Ende ME, Robinson DJ (2012) Photodynamic therapy with systemic meta-tetrahydroxyphenylchlorin in the treatment of anal intraepithelial neoplasia, grade 3. Lasers Surg Med 44(8):637-644. https://doi.org/10.1002/lsm.22062

42. Welbourn H, Duthie G, Powell J, Moghissi K (2014) Can photodynamic therapy be the preferred treatment option for anal intraepithelial neoplasia? Initial results of a pilot study. Photodiagn Photodyn Ther 11(1):20-21. https://doi.org/10.1016/j. pdpdt.2013.11.004

43. Palefsky JM, Berry JM, Jay N, Krogstad M, Da Costa M, Darragh TM, Lee JY (2006) A trial of SGN-00101 (HspE7) to treat highgrade anal intraepithelial neoplasia in HIV-positive individuals. Aids 20(8):1151-1155. https://doi.org/10.1097/01.aids. 0000226955.02719 .26

44. Swedish KA, Factor SH, Goldstone SE (2012) Prevention of recurrent high-grade anal neoplasia with quadrivalent human papillomavirus vaccination of men who have sex with men: a nonconcurrent cohort study. Clin Infect Dis 54(7):891-898. https://doi.org/10. 1093/cid/cir1036

45. Wilkin TJ, Chen H, Cespedes MS, Leon-Cruz JT, Godfrey C, Chiao EY, Bastow B, Webster-Cyriaque J, Feng Q, Dragavon J, Coombs RW, Presti RM, Saah A, Cranston RD (2018) A randomized, placebo-controlled trial of the quadrivalent human papillomavirus vaccine in human immunodeficiency virus-infected adults aged 27 years or older: AIDS Clinical Trials Group Protocol A5298. Clin Infect Dis 67(9):1339-1346. https://doi.org/10.1093/ $\mathrm{cid} / \mathrm{ciy} 274$

46. Geh I, Gollins S, Renehan A, Scholefield J, Goh V, Prezzi D, Moran B, Bower M, Alfa-Wali M, Adams R (2017) Association of Coloproctology of Great Britain \& Ireland (ACPGBI): guidelines for the management of cancer of the colon, rectum and anus (2017) - anal cancer. Color Dis 19(Suppl 1):82-97. https://doi.org/ 10.1111/codi.13709

47. Stewart DB, Gaertner WB, Glasgow SC, Herzig DO, Feingold D, Steele SR, Prepared on behalf of the clinical practice guidelines committee of the American Society of C, Rectal S (2018) The American Society of Colon and Rectal Surgeons Clinical Practice Guidelines for anal squamous cell cancers (Revised 2018). Dis Colon Rectum 61(7):755-774. https://doi.org/10.1097/DCR. 0000000000001114

48. Binda GA, Gagliardi G, Dal Conte I, Verra M, Cassoni P, Cavazzoni E, Stocco E, Delmonte S, De Nardi P, Sticchi L, Mistrangelo M (2019) Practice parameters for the diagnosis and treatment of anal intraepithelial neoplasia (AIN) on behalf of the Italian Society of Colorectal Surgery (SICCR). Tech Coloproctol 23(6):513-528. https://doi.org/10.1007/s10151-019-02019-5

Publisher's note Springer Nature remains neutral with regard to jurisdictional claims in published maps and institutional affiliations. 